\title{
Psychotropic drug use among older people with major neurocognitive disorder: a cross-sectional study based on Swedish national registries
}

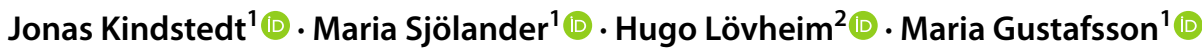

Received: 13 October 2020 / Accepted: 21 October 2021 / Published online: 4 November 2021

(c) The Author(s) 2021

\begin{abstract}
Aim Psychotropic medications include many drugs that may be inappropriate for older individuals with cognitive impairment. In Sweden, many people become registered in the Swedish Dementia Registry when they are diagnosed with major neurocognitive disorder (NCD). In this study, we aim to describe psychotropic drug use and associated factors among older Swedish people with major NCD.

Methods This study included 38,251 people $\geq 65$ years from the Swedish registry for cognitive/dementia disorders diagnosed during 2007-2017. Drug use was defined as one or more filled prescription(s) recorded in the Swedish Prescribed Drug Register during 1 July to 31 December 2017. Associations between psychotropics and age, sex, diagnosis date, Mini-Mental State Examination score and major NCD subtype were analysed through multiple logistic regression.

Results We found that $12.0 \%$ of the individuals filled at least one prescription for antipsychotics, $22.0 \%$ for anxiolytics, $23.0 \%$ for sedatives or hypnotics, $43.2 \%$ for antidepressants and $56.7 \%$ for antidementia drugs. In brief, psychotropic use was associated with female sex, higher age, longer time since diagnosis and specific subtypes of major NCD; the strongest association was found between antipsychotics and Lewy body dementia (odds ratio 2.40, 95\% confidence interval 2.04-2.82). Conclusion Psychotropic drugs were frequently dispensed among older Swedish people with major NCD. The use of antipsychotics and medications with sedative properties warrants concern, especially among those with Lewy body dementia who are severely sensitive to antipsychotics. A more restrictive prescribing pattern regarding these medications might reduce the risk of drug-related problems in this vulnerable group of people.
\end{abstract}

Keywords Older people $\cdot$ Psychotropic drugs $\cdot$ Neurocognitive disorders $\cdot$ Drug utilization

\section{Introduction}

Medications among older people often include psychotropic drugs, and a substantial proportion of these medications negatively alter dopamine or acetylcholine signalling and

\section{Key findings}

- Substantial proportions of individuals with major neurocognitive disorder had been dispensed psychotropic drugs that might be inappropriate for older people with cognitive impairment.

- Antipsychotic drug use was low compared to earlier findings.

- People with Lewy body dementia appear to be at particular risk of being exposed to psychotropic drugs, especially antipsychotics.

Jonas Kindstedt

jonas.kindstedt@umu.se

1 Department of Integrative Medical Biology, Umeå University, SE-901 87 Umeå, Sweden

2 Department of Community Medicine and Rehabilitation, Umeå University, SE-901 87 Umeå, Sweden thus becomes especially problematic among individuals with major neurocognitive disorder (NCD) [1, 2], formerly termed dementia. Moreover, there are several burdensome neuropsychiatric symptoms (NPS) that commonly emerge over time and vary significantly between major NCD subtypes [3-5]. Consequently, the treatment recommendations for NPS differ depending on the combination of symptoms present but often involve psychotropic drugs [6, 7]. A high prevalence of psychotropics has previously been documented among older people with major NCD living in Swedish specialized residential care units and nursing homes, institutions where both first- and second-generation antipsychotics have routinely been utilized in the treatment of NPS $[8,9]$. The risk of extrapyramidal symptoms and other adverse effects associated with antipsychotics are now well-documented, and these drugs should therefore be considered with extreme caution in people with major NCD [10-14]. Importantly, even short-term exposure to atypical antipsychotics is linked to a considerably higher risk of mortality and unplanned 
hospital admissions among these individuals [15-17]. Regarding other psychotropics, benzodiazepines are associated with both falls and delirium among older people [18, 19]. Similarly, sedating antihistamines (e.g. propiomazine and hydroxyzine) increase the risk of daytime sedation and anticholinergic side effects [20]. Tricyclic antidepressants are another example of anticholinergic drugs that may be problematic in cognitively impaired individuals [1, 21]. Instead, selective serotonin reuptake inhibitors (SSRIs) are generally the first recommended antidepressant in major NCD against both depressive symptoms and anxiety, or as an alternative to antipsychotics in the management of agitation and aggression [22]. Antidementia drugs (i.e. cholinesterase inhibitors and memantine) represent another class of psychotropics, highly relevant in major NCD. These drugs are not associated with the same risk as those previously described; on the contrary, it is desirable that treatment with cholinesterase inhibitors is routinely considered and evaluated in the management of Alzheimer's disease (AD) [20].

The Swedish registry for cognitive/dementia disorders (SveDem) started in 2007, and the number of registrations is continuously growing with almost 90,000 people registered by the end of 2019 [23]. In brief, the registry enables an important means for improving the quality of care for people with major NCD and provides information on various factors related to cognitive function, care level and overall functional state. Baseline registrations are carried out when people are newly diagnosed, either by primary care centres or different types of specialized care units, and follow-ups are often conducted on a yearly basis.

In this study, we aim to describe psychotropic drug use and associated factors in older Swedish people diagnosed with major NCD. The objectives are to estimate psychotropic drug use through dispensation data and explore the relationships between different classes of psychotropic drugs and major NCD subtypes.

\section{Method}

In this cross-sectional study, SveDem and the Swedish Prescribed Drug Register were linked through personal identity numbers, i.e. birth date followed by a unique four-digit number, to obtain information regarding psychotropic drugs among older people with major NCD.

\section{Study population}

Initially, all persons $\geq 65$ years registered in SveDem and with diagnosis dates from 1 May 2007 to 31 December 2017 were selected $(n=71,298)$, but only those who were alive on 31 December 2017 according to the Swedish Cause of Death Register were included in the analyses $(n=38,251)$. The study population comprised individuals living in ordinary housing and people in nursing homes or other forms of residential care.

\section{Outcomes and independent variables}

Our estimate of psychotropic drug use was based on dispensation data from Swedish community pharmacies. These data were recorded in the Swedish Prescribed Drug Register, from which we retrospectively gathered information on filled prescriptions for psychotropics within 6 months (1 July to 31 December 2017). Drug use was defined as one or more filled prescriptions during this period. This procedure was applied on substance level and then summarized for subgroups according to the Anatomical Therapeutic Chemical (ATC) Classification System. The ATC subgroups were antipsychotics (N05A), anxiolytics (N05B), sedatives and hypnotics (N05C), antidepressants (N06A) and antidementia drugs (N06D). In the appendix (eTable 1), we conducted a sensitivity analysis with a time frame of 4 months. Information regarding the date of diagnosis, test scores and subtype of major NCD was based on first-time registrations to SveDem. The NCD subtypes in SveDem had been translated as early-onset $\mathrm{AD}$, late-onset $\mathrm{AD}$, vascular dementia (VaD), mixed $\mathrm{AD}$ and $\mathrm{VaD}$, dementia with Lewy bodies (DLB), frontotemporal dementia, Parkinson's disease dementia (PDD), unspecified dementia and other dementias. These categories corresponded to specific codes in the 10th revision of the International Statistical Classification of Diseases and Related Health Problems (ICD-10). In a population of 21,885 people where cases of mixed, unspecified and other dementias had been excluded, we explored the associations between psychotropic drug use and four simplified major NCD subtypes during the same 6-month period. These subtypes were non-mixed type $\mathrm{AD}$, regardless of onset; frontotemporal dementia; non-mixed type $\mathrm{VaD}$; and major NCD subtypes associated with Lewy body pathology, which could be either DLB or PDD, and for which we applied the term Lewy body dementia (LBD).

\section{Statistics}

IBM SPSS Statistics version 25 and SAS Enterprise Guide 7.1 were used for all handling, calculations and analyses of data. We considered $p$-values $<0.05$ significant for all statistical tests, and odds ratios (ORs) were calculated with 95\% confidence intervals (CIs). Sex differences in proportions of individuals with filled prescriptions for psychotropics were 
analysed using the Pearson chi-square test. We applied multiple logistic regression to analyse the associations between ATC subgroups of psychotropics and major NCD subtypes. The adjusted regression models also included the following independent variables: age, sex, years since diagnosis and baseline Mini-Mental State Examination (MMSE) score. We assessed the linearity between independent continuous variables and the logarithms of the odds through visual inspection. In the appendix, the following analyses were performed: regression coefficients, standard errors and pseudo-R-squared measures (eTable 2); Pearson correlation matrix (eTable 3); crude ORs (eTable 4); and simple logistic regression regarding unspecified, mixed and other dementias (eTable 5).

\section{Ethical considerations}

The study was approved by the Regional Ethical Review Board in Umeå, Sweden (registration number 2017-256$31 \mathrm{M}$ ). Participants in SveDem have voluntarily registered after being provided with information that the data will be used for group-level analysis within the frameworks of research and quality improvement activities. After interlinking the SveDem-data with the Swedish Prescribed Drug Register, personal identification numbers were removed by the National Board of Health and Welfare. All individual personal data were stored in locked archives before, during and after the statistical analysis, and we only present information regarding medications, type of NCD and personal characteristics at the group level.

\section{Results}

The majority of the study population were registered from 2015 onwards (Fig. 1). Population characteristics and distribution of major NCD subtypes are presented in Table 1, and proportions of individuals with filled prescriptions for psychotropics are summarized in Table 2 . In brief, the five most common psychotropic drugs were memantine, donepezil, mirtazapine, oxazepam and zopiclone, all with prevalence estimates in the vicinity of $20 \%$ or above. Regarding antipsychotics, risperidone had been dispensed to the highest proportion of individuals, several times more than haloperidol. Moreover, apart from haloperidol, most antipsychotics were second-generation. Changing the time frame from 6 to 4 months did not proportionally decrease the percentages of psychotropics (eTable 1), a result that was consistent for all ATC subgroups. When investigating male and female sex separately, the proportions using N05A, N05B, N05C, N06A, N06D or any psychotropic among females were $12.2 \%, 24.1 \%, 24.1 \%, 46.3 \%, 56.6 \%$ and $84.3 \%$, respectively. The corresponding percentages for male sex were $11.7 \%$ $(p=0.133), 18.8 \%(p<0.001), 21.2 \%(p<0.001), 37.7 \%$ $(p<0.001), 56.9 \%(p=0.498)$ and $80.7 \%(p<0.001)$.
Fig. 1 Distribution of the study population $(n=38,251)$ based on their year of being registered to the Swedish registry for cognitive/dementia disorders

\section{Distribution of registration years for the study sample}

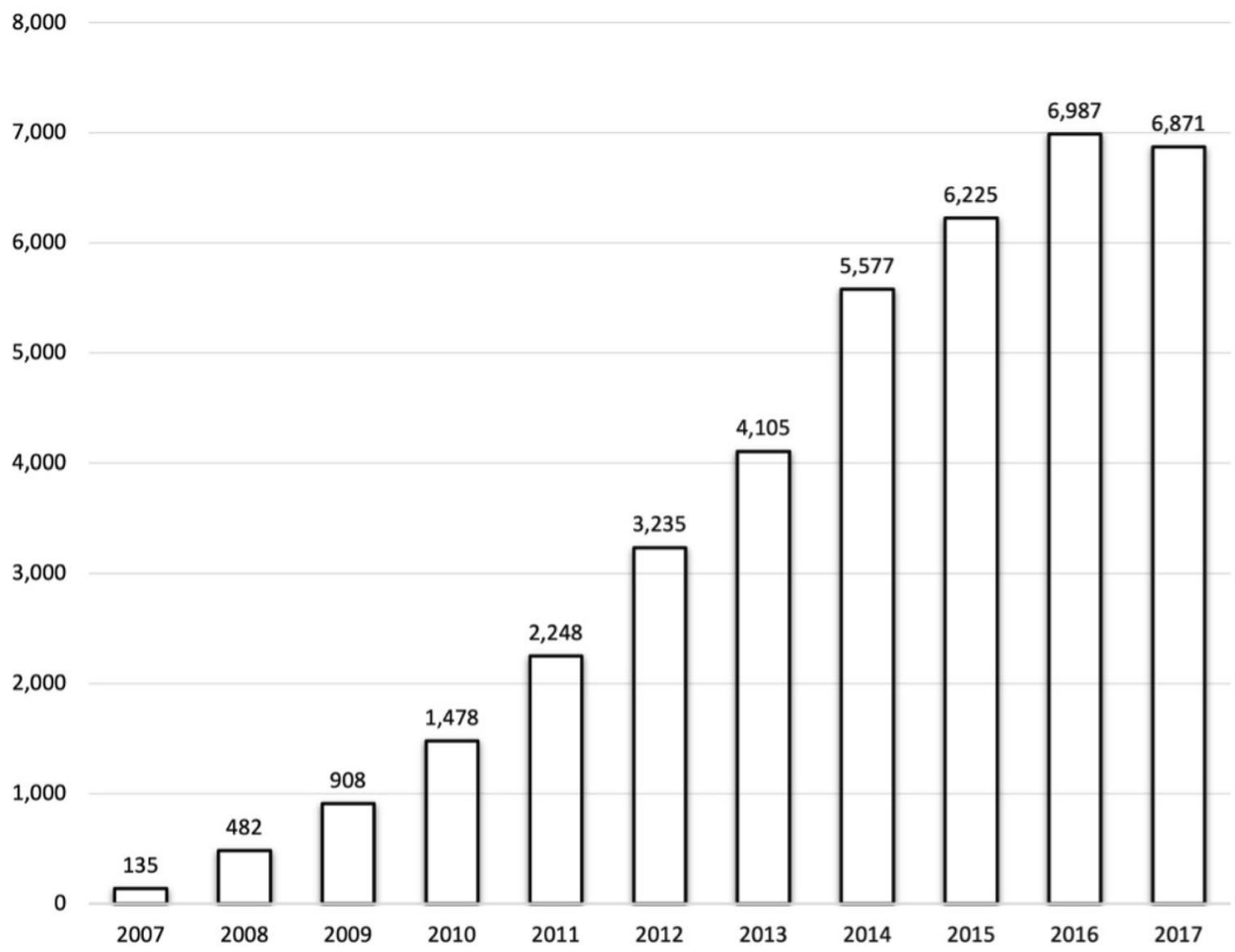


Table 1 Population characteristics for selected people from SveDem

\begin{tabular}{lll}
\hline Population characteristics & All selected individuals & $\begin{array}{l}\text { Individuals selected for } \\
\text { the regression analysis }\end{array}$ \\
\hline Number of individuals, $n$ & 38,251 & 21,885 \\
Female sex, \% $(n)^{\mathrm{a}}$ & $61.4(23,476)$ & $61.0(13,359)$ \\
Age (mean $\pm S D)^{\mathrm{b}}$ & $82.5 \pm 6.7$ & $81.8 \pm 6.7$ \\
Median age (IQR) & $83(9)$ & $82(10)$ \\
Early onset AD, \% $(n)$ & $1.9(729)$ & $3.3(729)$ \\
Late onset AD, \% $(n)$ & $32.9(12,595)$ & $57.6(12,595)$ \\
Mixed AD and VaD, \% $(n)$ & $18.7(7141)$ & $\mathrm{n} / \mathrm{a}$ \\
VaD, $\%(n)$ & $18.0(6900)$ & $31.5(6900)$ \\
DLB, \% $(n)$ & $1.8(674)$ & $3.1(674)$ \\
PDD, \% $(n)$ & $1.3(488)$ & $2.2(488)$ \\
Frontotemporal dementia, $\%(n)$ & $1.3(499)$ & $2.3(499)$ \\
Unspecified, \% $(n)$ & $21.6(8272)$ & $\mathrm{n} / \mathrm{a}$ \\
Other dementia type, $\%(n)$ & $2.5(953)$ & $\mathrm{n} / \mathrm{a}$ \\
Years since diagnosis $($ mean $)$ & 2.8 & 2.8 \\
Baseline MMSE score $(\text { mean })^{\mathrm{c}}$ & 21.5 & 21.7 \\
\hline
\end{tabular}

$A D$, Alzheimer's disease; $D L B$, dementia with Lewy bodies; MMSE, Mini-Mental State Examination; $P D D$, Parkinson's disease dementia; SveDem, Swedish registry for cognitive/dementia disorders; VaD, vascular dementia; $S D$, standard deviation; $I Q R$, interquartile range.

${ }^{a}$ Missing data in 13 and 8 cases, respectively.

${ }^{\mathrm{b}}$ Age refers to number of birthdays.

${ }^{\mathrm{c}}$ Missing information in 1696 cases and 844 cases, respectively.
Proportions of psychotropic drug users in terms of ATC subgroups and different subtypes of major NCD are presented in Table 3. The use of antipsychotics varied from $10.9 \%$ in $\mathrm{VaD}$ and late-onset $\mathrm{AD}$ to $25.4 \%$ in PDD. Quetiapine was more common than risperidone among people with LBD (i.e. either DLB or PDD), dispensed among $15.6 \%$ and $3.1 \%$ of the cases, respectively. The other ATC subgroups, except antidementia drugs, showed less variation between different types of major NCD. Filled prescriptions for antidepressants were found in over $40 \%$ of the study population, regardless of major NCD subtype. A more detailed investigation of the data regarding antidementia drugs in early- or late-onset $\mathrm{AD}$ showed that prescriptions for cholinesterase inhibitors (i.e. donepezil, rivastigmine or galantamine) had been filled in $56.9 \%$ of these cases; at least one cholinesterase inhibitor together with memantine was found in $15.1 \%$ of the population.

\section{Multiple logistic regression analyses}

The population selected for the logistic regression analysis of drug use in different subgroups of NCD numbered a total of 21,885 people, comprising 13,324 individuals with $\mathrm{AD}$, 6900 with VaD, 1161 with LBD and 499 with frontotemporal dementia. The results from the adjusted regression models are presented in Fig. 2. In brief, filled prescriptions for psychotropic drugs were significantly more common among women for all ATC subgroups other than antipsychotics and antidementia drugs. The latter was instead negatively associated with female sex. The direction of the relationship between psychotropic drug use and age varied across the drug classes, and except for antidementia drugs, longer time since diagnosis was consistently associated with higher use of psychotropics. Among the different major NCD subtypes, LBD indicated the strongest associations with drug use compared to $\mathrm{AD}$, and this observation was consistent for all ATC subgroups.

\section{Discussion}

\section{Findings}

When treating psychotropics as a homogenous group, our observed percentage of approximately $83 \%$ regarding the use of any psychotropic drug (Table 2) were between reported prevalence estimates of $88 \%$ [24] and 66\% [25] among nursing homes residents with major NCD. Moreover, three or more drugs from different ATC groups had occurred in 10.2\% of the study population (Table 2), but we cannot tell whether these results indicate actual polypharmacy or simply that one drug had replaced another. Regarding specific ATC subgroups other than antidementia drugs, most of our results seem lower than those found by Gustafsson et al. regarding people with major NCD, for example, $40 \%$ antipsychotic users in Swedish specialized residential care during 2005-2006 [9] and 
Table 2 Proportions of psychotropic drug users

\begin{tabular}{|c|c|}
\hline Psychotropic drugs & $\begin{array}{l}\text { Individuals with filled prescriptions, } \\
1 \text { July to } 31 \text { December } 2017, \%(n)\end{array}$ \\
\hline Any psychotropic drug & $82.9(31,712)$ \\
\hline Psychotropic drugs from $>1$ ATC-subgroup ${ }^{\mathrm{a}}$ & $27.9(10,687)$ \\
\hline Psychotropic drugs from $>2$ ATC-subgroups ${ }^{\mathrm{a}}$ & $10.2(3911)$ \\
\hline Psychotropic drugs from $>3$ ATC-subgroups ${ }^{\mathrm{a}}$ & $2.0(781)$ \\
\hline Antipsychotics (N05A) & $12.0(4594)$ \\
\hline Risperidone & $7.2(2762)$ \\
\hline Quetiapine & $1.7(662)$ \\
\hline Haloperidol & $1.5(569)$ \\
\hline Olanzapine & $1.4(530)$ \\
\hline Anxiolytics (N05B) & $22.0(8430)$ \\
\hline Oxazepam & $19.9(7626)$ \\
\hline Hydroxyzine & $1.4(526)$ \\
\hline Diazepam & $1.1(428)$ \\
\hline Sedatives or hypnotics (N05C) & $23.0(8783)$ \\
\hline Zopiclone & $16.0(6124)$ \\
\hline Clomethiazole & $4.0(1525)$ \\
\hline Zolpidem & $2.6(986)$ \\
\hline Melatonin & $2.0(774)$ \\
\hline Propiomazine & $1.0(400)$ \\
\hline Antidepressants (NO6A) & $43.2(16,511)$ \\
\hline Mirtazapine & $20.2(7711)$ \\
\hline Citalopram & $14.0(5366)$ \\
\hline Sertraline & $8.8(3349)$ \\
\hline Escitalopram & $3.9(1475)$ \\
\hline Venlafaxine & $1.8(695)$ \\
\hline Duloxetine & $0.9(353)$ \\
\hline Amitriptyline & $0.9(350)$ \\
\hline Antidementia drugs (N06D) & $56.7(21,686)$ \\
\hline Memantine & $26.8(10,269)$ \\
\hline Donepezil & $25.7(9828)$ \\
\hline Rivastigmine & $8.3(3185)$ \\
\hline Galantamine & $6.2(2384)$ \\
\hline
\end{tabular}

Substances with percentages $<0.5 \%$ are omitted.

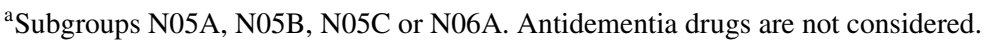

$19 \%$ antipsychotic users in different types of geriatric units in 2013 [26]. We found that $12.0 \%$ of the individuals had been dispensed antipsychotics (Table 2), and this variation may be due to heterogeneous study populations since institutionalized people are on average expected to be in a later and more severe stage of NCD, often with prominent NPS as a major reason for nursing home placement $[27,28]$. The differences could also reflect various efforts made in Sweden to improve drug therapy, such as the quality indicators issued by the National Board of Health and Welfare that were first released in 2004 [20]. Our proportion of antipsychotic users is similar to prevalence estimates from both France [29] and the UK [30], approximately $10 \%$ and $8-10 \%$, respectively, during similar time frames; however, those observational studies applied a more restrictive definition of drug use. On the other hand, the pooled prevalence of any antipsychotic reported by Kirkham et al. [31] was as high as $27.5 \%$ (95\% CI $25.7-29.3 \%, p<0.001)$. Even though our findings may not be conspicuous, there are still apparent differences between subtypes of major NCD, where LBD appears to be highly associated with the use of antipsychotics. In the present study, we found proportions of antipsychotic users to be $18.0 \%$ in DLB and $25.4 \%$ in PDD (Table 3). Similar proportions of antipsychotic drug users have been documented earlier in Sweden, for example, $>20 \%$ regarding residents with LBD features in Swedish nursing homes [32] and $16 \%$ among people with DLB in an earlier investigation of SveDem by Johnell et al. [33]. Our observations are probably due to the relatively high 
frequency of hallucinations and other psychotic symptoms in LBD compared to AD [3, 4, 34]. Nonetheless, the results call for concern since these individuals are extremely sensitive to antipsychotic drugs, with an increased risk of adverse drug reactions, such as malignant neuroleptic syndrome or further impairment of motor functions [35-39]. However, in our current study, it is uncertain whether antipsychotics have been utilized excessively, i.e. situations other than either schizophrenia or psychotic or severely aggressive behaviour; furthermore, there were no data regarding dosages and evaluation of treatments. On the positive side, most antipsychotics used in LBD were quetiapine, which appears to be the least unfavourable option [40]. Despite the large study population, we found no difference in antipsychotic drug use $(p=0.133)$, contrary to earlier findings by Lövheim et al. where the male and female proportions were $35.5 \%$ and $28.9 \%(\mathrm{p}<0.001)$, respectively [41]. Except for antidementia drugs, our data were in overall agreement with earlier observations that psychotropic drug use is more common among females [42, 43]. Previous studies have found that men and women with AD are different in terms of severity and types of NPS [44-46], but that is probably not the whole explanation. It is worrisome if systematic discrimination occurs with a lower threshold for utilizing psychotropics among women or if men are undertreated.

Zopiclone and oxazepam were frequently dispensed in the population, and these drugs are generally recommended in favour of sedating antihistamines and long-acting BZDs among older people [20,47]. In comparison, $1.1 \%$ of the persons had redeemed prescriptions for propiomazine, a figure which is approximately half that of an earlier prevalence estimate [48]. Nevertheless, even for short-intermediateacting BZDs and zopiclone, the associations with falls and hospitalizations may still be valid [49-53].

The proportion of antidepressant users was almost 50\% (Table 2) and might indicate a transition from antipsychotics
Fig. 2 Forest plot of adjusted odds ratios by psychotropic drug class. Alzheimer's disease was used as the reference category. Due to missing data regarding sex $(n=8)$ and MMSE score $(n=844)$, the analysis included 21,033 people. The odds ratios for age and MMSE are per year and unit of test score, respectively. LBD, Lewy body dementia; MMSE, Mini-Mental State Examination; PDD, Parkinson's disease dementia; $\mathrm{VaD}$, vascular dementia

towards antidepressants in the treatment of NPS, a trend earlier observed in the UK [54]. However, depression in major NCD is highly complex and could, for example, either be a prodrome of major NCD or a reaction to the declining functions and capabilities [55], and the Swedish Prescribed Drug Register provides no information as to whether antidepressants were prescribed to treat major depression, depressive symptoms or other NPS. Of note, mirtazapine appears to be the most utilized antidepressant among older Swedish people with major NCD, whereas national treatment guidelines recommended SSRIs as the first-line pharmacological option for depression, even in cases of co-existing cognitive disorder [47]. Plausible explanations could be the increased risk of hyponatraemia associated with citalopram and other SSRI [56], potential drug-drug interactions or simply that the physicians try to utilize the potential side effects of mirtazapine for purposes of weight gain or managing sleep disorders, which are common features of the NPS spectrum [3, 4]. Still, daytime sedation is common, and the association between mirtazapine and falls among older people is, to our knowledge, an area of limited research.

The high amounts of antidementia drugs in AD might be interpreted as a vague indicator that the need to improve cognitive symptoms and self-sustainability is acknowledged; however, the results do not confirm whether everyone that may benefit from cholinesterase inhibitors is considered for such treatments. Nor is it certain to what extent these treatments are properly evaluated over time, an aspect of particular relevance beyond the point of admission to residential

Table 3 Proportions of the study population $(n=38,251)$ who filled at least one prescription for psychotropic drugs within different major NCD subtypes

\begin{tabular}{|c|c|c|c|c|c|}
\hline Major NCD subtype & $\begin{array}{l}\text { Antipsychotics } \\
\text { (N05A), \% (n) }\end{array}$ & $\begin{array}{l}\text { Anxiolytics } \\
\text { (N05B), \% (n) }\end{array}$ & $\begin{array}{l}\text { Sedatives and hypnotics } \\
\text { (N05C), \% (n) }\end{array}$ & $\begin{array}{l}\text { Antidepressants } \\
\text { (N06A), \% (n) }\end{array}$ & $\begin{array}{l}\text { Antidementia } \\
\text { drugs (N06D), } \\
\%(n)\end{array}$ \\
\hline Early onset AD & $14.1(103)$ & $21.7(158)$ & $19.5(142)$ & $44.4(324)$ & $76.8(560)$ \\
\hline Late onset AD & $10.9(1373)$ & $21.1(2662)$ & $21.0(2639)$ & $42.3(5329)$ & $75.9(9557)$ \\
\hline Mixed $\mathrm{AD}$ and $\mathrm{VaD}$ & $11.3(810)$ & $21.1(1510)$ & $25.2(1801)$ & $41.1(2935)$ & $69.1(4932)$ \\
\hline $\mathrm{VaD}$ & $10.9(755)$ & $21.6(1488)$ & $25.4(1753)$ & $44.4(3061)$ & $20.5(1417)$ \\
\hline DLB & $18.0(121)$ & $21.2(143)$ & $26.3(177)$ & $48.5(327)$ & $82.3(555)$ \\
\hline PDD & $25.4(124)$ & $20.5(100)$ & $23.8(116)$ & $51.4(251)$ & $70.9(346)$ \\
\hline Frontotemporal dementia & $17.0(85)$ & $19.0(95)$ & $22.6(113)$ & $46.5(232)$ & $19.2(96)$ \\
\hline Unspecified dementia & $13.2(1096)$ & $24.9(2063)$ & $22.1(1830)$ & $43.8(3627)$ & $46.5(3843)$ \\
\hline Other dementia type & $13.3(127)$ & $22.1(211)$ & $22.2(212)$ & $44.6(425)$ & $39.9(380)$ \\
\hline
\end{tabular}

$A D$, Alzheimer's disease; $D L B$, dementia with Lewy bodies; $P D D$, Parkinson's disease dementia; $V a D$, vascular dementia. 
Odds ratio with $95 \%$ confidence interval

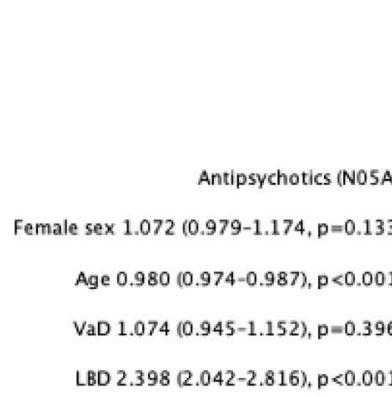

Frontotemporal dementia $1.733(1.347-2.230), \mathrm{p}<0.001$

Years since diagnosis $1.149(1.129-1.170), p<0.001$

Baseline MMSE score $0.955(0.946-0.963), p<0.001$

Anxiolytics (N058)

Female sex $1.324(1.232-1.423), p<0.001$

Age 1.004 (0.999-1.009), $\mathrm{p}=0.140$

$\operatorname{VaD} 1.085(1.006-1.170), p=0.034$

LBD $1.238(1.059-1.447), p=0.007$

Frontotemporal dementia $0.970(0.760-1.238), p=0.807$

Years since diagnosis $1.149(1.133-1.166), p<0.001$

Baseline MMSE score $0.958(0.951-0.965), p<0.001$

Sedatives and hypnotics (N05C)

Female sex $1,252(1.168-1.342), p<0.001$

Age 1.011 (1.005-1.016), p<0.001

$\operatorname{VaD} 1.316(1.225-1.414), p<0.001$

LBD $1.442(1.246-1.668), p<0.001$

Frontotemporal dementia $1.201(0.960-1.503), p=0.109$

Years since diagnosis $1.020(1.005-1.035), p=0.007$

Baseline MMSE score $0.999(0.992-1.006), p=0.853$

Antidepressants (N06A)

Female sex $1.471(1.388-1.560), p<0.001$

Age $0.984(0.979-0.988), p<0.001$

VaD $1.209(1.136-1.286), p<0.001$

LBD 1.554 (1.369-1.764), p<0.001

Frototemporal dementia $1.177(0.974-1.422), p=0.091$

Years since diagnosis $1.103(1.089-1.116), p<0.001$

Baseline MMSE score $1.000(0.994-1.006), p=0.899$

Antidementia drugs (N06D)

Female sex $0.873(0.994-1.006), p<0.001$

Age $0.952(0.947-0.957), p<0.001$

$\operatorname{VaD} 0.078(0.073-0.084), p<0.001$

LBD $0.848(0.728-0.988), p=0.034$

Frontotemporal dementia $0.047(0.037-0.061), p<0.001$

Years since diagnosis $0.936(0.923-0.950), p<0.001$

Baseline MMSE score $1.025(1.017-1.032), p<0.001$
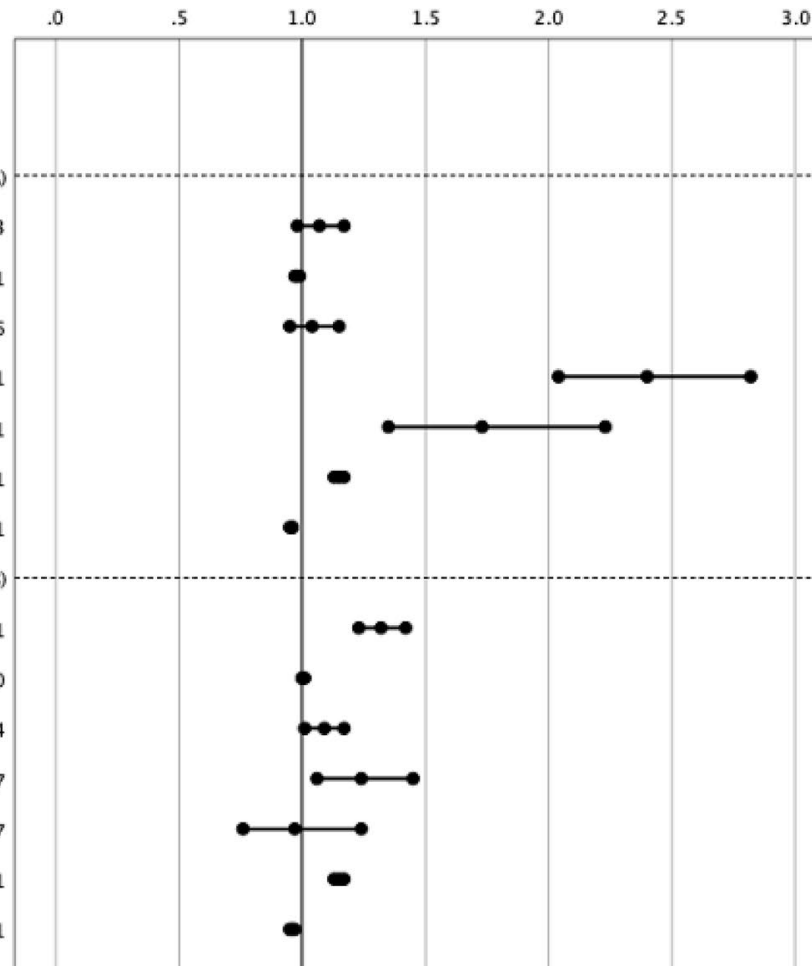

(n)

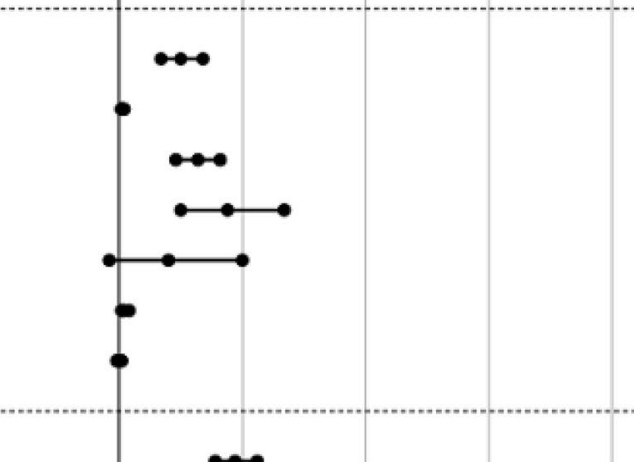


care or in other severe stages of major NCD where the chance of impeding cognitive decline may be less likely. On the other hand, the numbers in Fig. 1 show that most of the study population had been diagnosed within 3 years before the end of 2017, and this group could presumably comprise many cases of relatively mild or moderate AD, which are the original indications for most antidementia drugs. Cholinesterase inhibitors may, in addition to improving ratings of cognitive functions, global assessments and activities of daily living, also be beneficial for alleviating many of the characterizing and burdensome NPS in LBD [57-59], which may explain the relatively minor difference compared to AD.

\section{Strengths}

The number of reporting primary care units had surpassed 900 (approximately $80 \%$ of all primary care centres) by the end of 2017 and had provided approximately $45 \%$ of all new registrations during that period [60]. The studied individuals should therefore be representative of the two main settings where cognitive examinations in Sweden are conducted, i.e. primary and specialized care units. Moreover, the cases of AD were similar to previous worldwide prevalence estimates [61]. The size of the data set is another important factor to consider, even though the exact coverage and representativity remain uncertain. Furthermore, dispensation data can, compared with prescription records, provide more accurate estimations regarding ongoing treatments and actual drug exposure. In Sweden, prescriptions for subsidized medicines are generally not issued for more than 3 months at a time, and dispensation data for individuals with at least $50 \%$ of days covered with drug supply for long-term treatments were therefore most likely included in our statistical presentation and analysis. Decreasing the period from 6 to 4 months, a more conservative approach to define drug users, had little impact on prescription fills (Appendix, eTable 1).

\section{Limitations and risk of bias}

To compare well-defined categories in the regression analysis, we removed all individuals diagnosed with mixed, uncertain, or other dementia from the regression analysis, and the uncertainties regarding the large proportions of such diagnoses should be mentioned in terms of potential bias risk. It is reasonable to suspect that the unspecified cases represented a considerable number of persons with LBD, especially compared with other prevalence estimates, which suggest a figure around 5-10\% [62-64] compared to our observed proportion of $3.1 \%$ (Table 1). Although less than $5 \%$ of all SveDem registrations during 2007-2017 had been changed during follow-up [60], uncommon types of major NCD, e.g. LBD and frontotemporal dementia, may in many cases still have been labelled as unspecified dementia during the initial primary care examination and instead been referred to specialized care units for a re-evaluation of the diagnosis. Missing data regarding the MMSE result and the deletion of those individuals in the multiple regression models is another potential source of bias that should be considered when interpreting the adjusted ORs, especially since those cognitive evaluations might have been more of a standard procedure in certain reporting units, i.e. specialized versus primary care.

In nursing homes and similar institutions, insufficient staff and caregiver distress may be barriers against the implementation of more rational non-pharmacological alternatives to antipsychotics [25, 65-67], but we had no information about NPS and nursing home placement for the time period of interest. Among other potential confounders, socioeconomic disadvantage deserves to be mentioned [68], and although there are many aspects of socioeconomic status, this factor is perhaps less important in Sweden where most prescription medications are covered by a subsidiary system with a maximum 12-month cost of approximately 2350 SEK. Another limitation is that our definition of drug use did not capture dosage regimen, total drug supply, indication for therapy and treatment duration, and these factors should ideally be given more focus to better assess the appropriateness of medication use.

\section{Conclusions}

Psychotropic drugs were frequently dispensed among older Swedish people with major NCD. The percentages of antipsychotics and drugs with sedative properties are especially relevant from a risk perspective. The association between antipsychotic drug use and people with LBD warrants particular concern since these individuals are highly sensitive to adverse drug reactions from such medications. Moreover, antidepressants and antidementia drugs had been dispensed in about half of the study population. Despite being potential indicators of deliberate and rational medication use, these long-term treatments still require continuous evaluation regarding effect versus safety. More restrictive prescribing of psychotropics may further reduce drug-related problems among individuals with major NCD; however, longitudinal and comparative approaches are needed to better assess the appropriateness of psychotropic drug use in this vulnerable group of people.

Supplementary Information The online version contains supplementary material available at https://doi.org/10.1007/s00228-021-03241-7.

Acknowledgements We want to express our gratitude to all participants, reporting units, coordinators and steering board members in the Swedish registry for cognitive/dementia disorders (www.svedem.se) for providing us with the basic data necessary for this study. We also want to thank Eva Sönnerstam, who contributed during our application for ethical approval and acquisition of registry data. 
Author contribution JK wrote the manuscript. JK, MS and HL were involved in the statistical analysis. JK, MS and MG developed the original study design. JK, MS, HL and MG contributed to the revision of the study design, contributed to the review process of the manuscript, approved the final version and will ensure that issues related to the accuracy or integrity of the work are investigated and resolved.

Funding Open access funding provided by Umeå University. The Swedish Dementia Association.

Data availability The datasets generated during and/or analysed in this study are available from the corresponding author upon reasonable request.

Code availability Not applicable.

\section{Declarations}

Ethics approval and consent to participate The Ethical Review Board in Umeå approved this study (registration number 2017-256-31 M).

Conflict of interest Hugo Lövheim is a member of the steering committee of the Swedish registry for cognitive/dementia disorders (SveDem). The other authors declare no competing interests.

Open Access This article is licensed under a Creative Commons Attribution 4.0 International License, which permits use, sharing, adaptation, distribution and reproduction in any medium or format, as long as you give appropriate credit to the original author(s) and the source, provide a link to the Creative Commons licence, and indicate if changes were made. The images or other third party material in this article are included in the article's Creative Commons licence, unless indicated otherwise in a credit line to the material. If material is not included in the article's Creative Commons licence and your intended use is not permitted by statutory regulation or exceeds the permitted use, you will need to obtain permission directly from the copyright holder. To view a copy of this licence, visit http://creativecommons.org/licenses/by/4.0/.

\section{References}

1. Moore AR, O'Keeffe ST (1999) Drug-induced cognitive impairment in the elderly. Drugs Aging 15(1):15-28

2. Mangoni AA, Jackson SHD (2004) Age-related changes in pharmacokinetics and pharmacodynamics: basic principles and practical applications. Br J Clin Pharmacol 57(1):6-14

3. Mukherjee A, Biswas A, Roy A, Biswas S, Gangopadhyay G, Das SK (2017) Behavioural and psychological symptoms of dementia: correlates and impact on caregiver distress. Dement Geriatr Cogn Dis Extra 7(3):354-365

4. Chiu MJ, Chen TF, Yip PK, Hua MS, Tang LY (2006) Behavioral and psychologic symptoms in different types of dementia. J Formos Med Assoc 105(7):556-562

5. Engelborghs S, Maertens K, Nagels G, Vloeberghs E, Marien P, Symons A et al (2005) Neuropsychiatric symptoms of dementia: cross-sectional analysis from a prospective, longitudinal Belgian study. Int J Geriatr Psychiatry 20(11):1028-1037

6. Corbett A, Smith J, Creese B, Ballard C (2012) Treatment of behavioral and psychological symptoms of Alzheimer's disease. Curr Treat Options Neurol 14(2):113-125

7. Tible OP, Riese F, Savaskan E, von Gunten A (2017) Best practice in the management of behavioural and psychological symptoms of dementia. Ther Adv Neurol Disord 10(8):297-309
8. Olsson J, Bergman A, Carlsten A, Oke T, Bernsten C, Schmidt IK et al (2010) Quality of drug prescribing in elderly people in nursing homes and special care units for dementia: a cross-sectional computerized pharmacy register analysis. Clin Drug Investig 30(5):289-300

9. Gustafsson M, Karlsson S, Gustafson Y, Lövheim H (2013) Psychotropic drug use among people with dementia-a six-month follow-up study. BMC Pharmacol Toxicol 14:56

10. Lee PE, Gill SS, Freedman M, Bronskill SE, Hillmer MP, Rochon PA (2004) Atypical antipsychotic drugs in the treatment of behavioural and psychological symptoms of dementia: systematic review. BMJ 329(7457):75

11. Schneider LS, Tariot PN, Dagerman KS, Davis SM, Hsiao JK, Ismail MS et al (2006) Effectiveness of atypical antipsychotic drugs in patients with Alzheimer's disease. N Engl J Med 355(15):1525-1538

12. Sink KM, Holden KF, Yaffe K (2005) Pharmacological treatment of neuropsychiatric symptoms of dementia: a review of the evidence. JAMA 293(5):596-608

13. Chan WC, Lam LC, Choy CN, Leung VP, Li SW, Chiu HF (2001) A double-blind randomised comparison of risperidone and haloperidol in the treatment of behavioural and psychological symptoms in Chinese dementia patients. Int J Geriatr Psychiatry 16(12):1156-1162

14. Gill SS, Bronskill SE, Normand SL, Anderson GM, Sykora K, Lam K et al (2007) Antipsychotic drug use and mortality in older adults with dementia. Ann Intern Med 146(11):775-786

15. Rochon PA, Normand SL, Gomes T, Gill SS, Anderson GM, Melo M et al (2008) Antipsychotic therapy and short-term serious events in older adults with dementia. Arch Intern Med 168(10):1090-1096

16. Langballe EM, Engdahl B, Nordeng H, Ballard C, Aarsland D, Selbaek G (2014) Short- and long-term mortality risk associated with the use of antipsychotics among 26,940 dementia outpatients: a population-based study. Am J Geriatr Psychiatry 22(4):321-331

17. Schwertner E, Secnik J, Garcia-Ptacek S, Johansson B, Nagga K, Eriksdotter M et al (2019) Antipsychotic treatment associated with increased mortality risk in patients with dementia. A registry-based observational cohort study. J Am Med Dir Assoc 20(3):323-9.e2

18. Hanlon JT, Horner RD, Schmader KE, Fillenbaum GG, Lewis IK, Wall WE Jr et al (1998) Benzodiazepine use and cognitive function among community-dwelling elderly. Clin Pharmacol Ther 64(6):684-692

19. Davies EA, O’Mahony MS (2015) Adverse drug reactions in special populations - the elderly. Br J Clin Pharmacol 80(4):796-807

20. The National Board of Health and Welfare (2017) Indikatorer för god läkemedelsterapi hos äldre [Eng. Indicators for evaluating the quality of older people's drug therapy]. Accessed 5 August 2021. Available from: https://www.socialstyrelsen.se/globalassets/ sharepoint-dokument/artikelkatalog/ovrigt/2017-6-7.pdf

21. Cancelli I, Beltrame M, Gigli GL, Valente M (2009) Drugs with anticholinergic properties: cognitive and neuropsychiatric sideeffects in elderly patients. Neurol Sci 30(2):87-92

22. Masopust J, Protopopová D, Vališ M, Pavelek Z, Klímová B (2018) Treatment of behavioral and psychological symptoms of dementias with psychopharmaceuticals: a review. Neuropsychiatr Dis Treat 14:1211-1220

23. Swedish registry for cognitive/dementia disorders (SveDem) (2020). Annual report 2019. Accessed 1 August 2021. Available from: https://www.ucr.uu.se/svedem/om-svedem/arsrapporter/ svedem-arsrapport-2019/viewdocument/1000

24. Selbaek G, Kirkevold O, Engedal K (2008) The course of psychiatric and behavioral symptoms and the use of psychotropic medication in patients with dementia in Norwegian nursing homes-a 12-month follow-up study. Am J Geriatr Psychiatry 16(7):528-536 
25. Zuidema SU, de Jonghe JF, Verhey FR, Koopmans RT (2011) Psychotropic drug prescription in nursing home patients with dementia: influence of environmental correlates and staff distress on physicians' prescription behavior. Int Psychogeriatr 23(10):1632-1639

26. Gustafsson M, Isaksson U, Karlsson S, Sandman PO, Lovheim H (2016) Behavioral and psychological symptoms and psychotropic drugs among people with cognitive impairment in nursing homes in 2007 and 2013. Eur J Clin Pharmacol 72(8):987-994

27. Afram B, Stephan A, Verbeek H, Bleijlevens MH, Suhonen R, Sutcliffe C et al (2014) Reasons for institutionalization of people with dementia: informal caregiver reports from 8 European countries. J Am Med Dir Assoc 15(2):108-116

28. Stephan A, Afram B, Koskenniemi J, Verbeek H, Soto ME, Bleijlevens MH et al (2015) Older persons with dementia at risk for institutionalization in eight European countries: a crosssectional study on the perceptions of informal caregivers and healthcare professionals. J Adv Nurs 71(6):1392-1404

29. Gallini A, Andrieu S, Donohue JM, Oumouhou N, LapeyreMestre M, Gardette V (2014) Trends in use of antipsychotics in elderly patients with dementia: impact of national safety warnings. Eur Neuropsychopharmacol 24(1):95-104

30. Stocks SJ, Kontopantelis E, Webb RT, Avery AJ, Burns A, Ashcroft DM (2017) Antipsychotic prescribing to patients diagnosed with dementia without a diagnosis of psychosis in the context of national guidance and drug safety warnings: longitudinal study in UK general practice. Drug Saf 40(8):679-692

31. Kirkham J, Sherman C, Velkers C, Maxwell C, Gill S, Rochon $P$ et al (2017) Antipsychotic use in dementia. Can J Psychiatry 62(3):170-181

32. Zahirovic I, Torisson G, Wattmo C, Londos E (2018) Psychotropic and anti-dementia treatment in elderly persons with clinical signs of dementia with Lewy bodies: a cross-sectional study in 40 nursing homes in Sweden. BMC Geriatr 18(1):50

33. Johnell K, Religa D, Eriksdotter M (2013) Differences in drug therapy between dementia disorders in the Swedish dementia registry: a nationwide study of over 7,000 patients. Dement Geriatr Cogn Disord 35(5-6):239-248

34. Aarsland D, Ballard C, Larsen JP, McKeith I (2001) A comparative study of psychiatric symptoms in dementia with Lewy bodies and Parkinson's disease with and without dementia. Int J Geriatr Psychiatry 16(5):528-536

35. McKeith I, Fairbairn A, Perry R, Thompson P, Perry E (1992) Neuroleptic sensitivity in patients with senile dementia of Lewy body type. BMJ 305(6855):673-678

36. McKeith IG, Dickson DW, Lowe J, Emre M, O'Brien JT, Feldman H et al (2005) Diagnosis and management of dementia with Lewy bodies: third report of the DLB Consortium. Neurology 65(12):1863-1872

37. Aarsland D, Perry R, Larsen JP, McKeith IG, O’Brien JT, Perry EK et al (2005) Neuroleptic sensitivity in Parkinson's disease and parkinsonian dementias. J Clin Psychiatry 66(5):633-637

38. Weintraub D, Chiang C, Kim HM, Wilkinson J, Marras C, Stanislawski B et al (2016) Association of antipsychotic use with mortality risk in patients with Parkinson disease. JAMA Neurol 73(5):535-541

39. Fernandez HH, Trieschmann ME, Friedman JH (2003) Treatment of psychosis in Parkinson's disease: safety considerations. Drug Saf 26(9):643-659

40. Armstrong MJ, Weintraub D (2017) The case for antipsychotics in dementia with Lewy bodies. Mov Disord Clin Pract 4(1):32-35

41. Lövheim H, Sandman PO, Karlsson S, Gustafson Y (2009) Sex differences in the prevalence of behavioral and psychological symptoms of dementia. Int Psychogeriatr 21(3):469-475

42. Vittadini G, Beghi M, Mezzanzanica M, Ronzoni G, Cornaggia CM (2014) Use of psychotropic drugs in Lombardy in time of economic crisis (2007-2011): a population-based study of adult employees. Psychiatry Res 220(1-2):615-622

43. Boyd A, Van de Velde S, Pivette M, Ten Have M, Florescu S, O'Neill S et al (2015) Gender differences in psychotropic use across Europe: results from a large cross-sectional, populationbased study. Eur Psychiatry 30(6):778-788

44. Inamura $\mathrm{K}$, Shinagawa $\mathrm{S}$, Tsuneizumi $\mathrm{Y}$, Nagata $\mathrm{T}$, Tagai $\mathrm{K}$, Nukariya K et al (2020) Sex differences in the severity of neuropsychiatric symptoms and their relationship with clinicodemographic and psychosocial factors in patients with amnestic mild cognitive impairment and mild Alzheimer's disease. Aging Ment Health 24(3):431-438

45. Xing Y, Tang Y, Jia J (2015) Sex differences in neuropsychiatric symptoms of Alzheimer's disease: the modifying effect of apolipoprotein E \&4 status. Behav Neurol 2015:275256

46. Colombo D, Caltagirone C, Padovani A, Sorbi S, Spalletta G, Simoni L et al (2018) Gender differences in neuropsychiatric symptoms in mild to moderate Alzheimer's disease patients undergoing switch of cholinesterase inhibitors: a post hoc analysis of the EVOLUTION Study. J Womens Health (Larchmt) 27(11):1368-1377

47. Swedish Medical Products Agency (2008) Läkemedelsbehandling och bemötande vid Beteendemässiga och Psykiska Symptom vid Demenssjukdom-BPSD [Eng. Pharmacological treatment and management of behavioural and psychological symptoms of dementia-BPSD]. Information from the Swedish medical products Agency

48. Hovstadius B, Petersson G, Hellström L, Ericson L (2014) Trends in inappropriate drug therapy prescription in the elderly in Sweden from 2006 to 2013: assessment using national indicators. Drugs Aging 31(5):379-386

49. Yu NW, Chen PJ, Tsai HJ, Huang CW, Chiu YW, Tsay WI et al (2017) Association of benzodiazepine and Z-drug use with the risk of hospitalisation for fall-related injuries among older people: a nationwide nested case-control study in Taiwan. BMC Geriatr 17(1): 140

50. Wang PS, Bohn RL, Glynn RJ, Mogun H, Avorn J (2001) Zolpidem use and hip fractures in older people. J Am Geriatr Soc 49(12):1685-1690

51. Landi F, Onder G, Cesari M, Barillaro C, Russo A, Bernabei R (2005) Psychotropic medications and risk for falls among community-dwelling frail older people: an observational study. J Gerontol A Biol Sci Med Sci 60(5):622-626

52. de Vries OJ, Peeters G, Elders P, Sonnenberg C, Muller M, Deeg DJ et al (2013) The elimination half-life of benzodiazepines and fall risk: two prospective observational studies. Age Ageing 42(6):764-770

53. van Strien AM, Koek HL, van Marum RJ, Emmelot-Vonk MH (2013) Psychotropic medications, including short acting benzodiazepines, strongly increase the frequency of falls in elderly. Maturitas 74(4):357-362

54. Martinez C, Jones RW, Rietbrock S (2013) Trends in the prevalence of antipsychotic drug use among patients with Alzheimer's disease and other dementias including those treated with antidementia drugs in the community in the UK: a cohort study. BMJ Open 3(1)

55. Bennett S, Thomas AJ (2014) Depression and dementia: cause, consequence or coincidence? Maturitas 79(2):184-190

56. Leth-Moller KB, Hansen AH, Torstensson M, Andersen SE, Odum L, Gislasson G et al (2016) Antidepressants and the risk of hyponatremia: a Danish register-based population study. BMJ Open 6(5):e011200

57. Meng YH, Wang PP, Song YX, Wang JH (2019) Cholinesterase inhibitors and memantine for Parkinson's disease dementia and Lewy body dementia: a meta-analysis. Exp Ther Med 17(3):1611-1624 
58. Matsunaga S, Kishi T, Yasue I, Iwata N (2015) Cholinesterase inhibitors for Lewy body disorders: a meta-analysis. Int J Neuropsychopharmacol 19(2)

59. Rolinski M, Fox C, Maidment I, McShane R (2012) Cholinesterase inhibitors for dementia with Lewy bodies, Parkinson's disease dementia and cognitive impairment in Parkinson's disease. Cochrane Database Syst Rev (3):Cd006504

60. Swedish registry for cognitive/dementia disorders (SveDem) (2018) Annual report 2017. Accessed 30 July 2021. Available at: https://www.ucr.uu.se/svedem/om-svedem/arsrapporter/svedemarsrapport-2017/viewdocument/828

61. Prince M, Bryce R, Albanese E, Wimo A, Ribeiro W, Ferri CP (2013) The global prevalence of dementia: a systematic review and metaanalysis. Alzheimers Dement 9(1):63-75.e2

62. Kane JPM, Surendranathan A, Bentley A, Barker SAH, Taylor JP, Thomas AJ et al (2018) Clinical prevalence of Lewy body dementia. Alzheimers Res Ther 10(1):19

63. Aarsland D, Zaccai J, Brayne C (2005) A systematic review of prevalence studies of dementia in Parkinson's disease. Mov Disord 20(10):1255-1263
64. Vann Jones SA, O'Brien JT (2014) The prevalence and incidence of dementia with Lewy bodies: a systematic review of population and clinical studies. Psychol Med 44(4):673-683

65. Haasum Y, Fastbom J, Johnell K (2012) Institutionalization as a risk factor for inappropriate drug use in the elderly: a Swedish nationwide register-based study. Ann Pharmacother 46(3):339-346

66. Cousins JM, Bereznicki LR, Cooling NB, Peterson GM (2017) Prescribing of psychotropic medication for nursing home residents with dementia: a general practitioner survey. Clin Interv Aging 12:1573-1578

67. Kleijer BC, van Marum RJ, Frijters DH, Jansen PA, Ribbe MW, Egberts AC et al (2014) Variability between nursing homes in prevalence of antipsychotic use in patients with dementia. Int Psychogeriatr 26(3):363-371

68. Wamala S, Merlo J, Bostrom G, Hogstedt C, Agren G (2007) Socioeconomic disadvantage and primary non-adherence with medication in Sweden. Int J Qual Health Care 19(3):134-140

Publisher's Note Springer Nature remains neutral with regard to jurisdictional claims in published maps and institutional affiliations. 